\title{
Using a learning log to support students understanding and engagement within a research module
}

\author{
Marie Kerin ${ }^{1}$ and Owen Doody ${ }^{2 *}$
}

*Correspondence: owen.doody@ul.ie

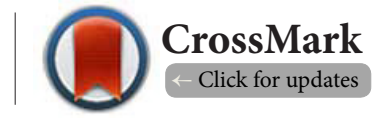

'Undergraduate student, General nursing, University of Limerick, Ireland.

${ }^{2}$ Lecturer, Department of Nursing and Midwifery, University of Limerick, Ireland.

\begin{abstract}
Evidenced-based practice research is a common phrase in discussions regarding patient care. As a profession nursing/midwifery has a responsibility to educate their students with a primary focus on research based practice. Within education assessment is a significant feature which influences, what and how students decide to learn and generally learning is dependent on the quality of assessment. One method that has become popular to support learning and assessment is the use of a learning log. This article presents the use of a learning log as a learning and assessment process for undergraduate nursing and midwifery students and presents a student and module leader reflective comments. The use of a learning log was driven by the educators desire to be innovative when delivering a research module to students who often hold the view that research is a difficult and undesirable subject to study.
\end{abstract}

Keywords: Learning log, research, student, nursing/midwifery education, undergraduate, module

\section{Introduction}

Spanning generation's researchers have introduced, studied, shared and utilised the concept of research within nursing/

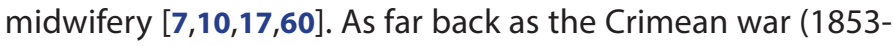
1856), Florence Nightingale collected data on mortality rates, igniting nursing/midwifery research and evidence-based practice. Essential to the development of evidence-based healthcare is nurse/midwife education, creating an ethos where research findings are understood and translated into practice (Thompson et al., 2014). Research is the driving force used to change practice, education and health policy [29] and nurses/ midwives are expected to; defend their actions with research evidence, undertake research to improve practice and patient well-being, and use evidence to develop protocols and improve outcomes [11]. In the quest to provide the best possible care, there is a requirement for an understanding of evidence and the knowledge upon which that evidence is based [62]. The use of evidence (i.e. research) is the foundation of nursing/ midwifery practice and educating students in the terminology and practice of research is difficult [31]. In educating students, a positive attitude to research is essential, otherwise understanding and utilisation will be limited (Squire et al., 2011). While understanding evidence and its use in practice is of a high priority (Pearce et al., 2013), students find learning about research difficult and challenging $[56,79]$. Therefore research as a subject compares less favourable to other subjects on the syllabus and is not always seen as clinically applicable [32,74].

Given students perception that research is difficulty and not relevant to practice, students express a lack of interest; in research as a subject [41] and the fact that research helps guide practice improvements and evidence-based practice [48]. There is a need to incorporate research content within undergraduate curriculum to enable students understand the research process and the relevance of evidence-based practice [37]. With this in mind the second author (module leader) set themselves the task of involving their students in; the topic matter, participating in classes and tutorials, and to be interested to research and think critically about the subject in a way that is wider than the recommended reading [21]. This is in line with international professional nursing/midwifery bodies, which identify that pre-registration education programmes should empower students to cultivate their ability to analyse, critical think, problem solving and reflect $[1,59]$. Conscious of this and to prepare students for their encounters of a multifaceted, ever changing healthcare environment [21], the second author developed a formative and summative assessment 
Kerin et al. Journal of Nursing 2018,

http://www.hoajonline.com/journals/pdf/2056-9157-5-5.pdf

doi: $10.7243 / 2056-9157-5-5$

(present knowledge and a learning log) specific to a module on research as part of an undergraduate course. The student group comprised of BSc (4 year degree programme) students from intellectual disability, mental health, general nursing and midwifery programmes $(n=120)$. To engage students in examining, debating and applying the content of the module, rather than absorbing the information passively, an assessment approach that promoted active engagement was required $[21,66]$. This article focuses on the use of a learning log as an assessment method within an undergraduate research module and incorporates reflective comments from both a student (first author) and the module leader (second author).

\section{Learning $\log$ and rational for its use}

A learning log is a vessel for writing that is logged over a period of time and complements a programme of learning, a placement experience or a research project [54] and encourages students to be aware of the process of learning [40]. As far back as 1961, Kimble described learning as a lasting alteration in ones behaviour, instigated by practice and experience [39]. Using a learning log promotes training as a unique process for each individual that encapsulates many different phases of capability not just competence [53]. Keeping a learning log helps one to reflect in a structured way, by allowing reflection on thoughts, understanding and ideas about a topic in question [22] and enables individual learning [6]. However; within the process many often neglect the reflective phase which is essential to be developed during the pre-qualification years as it provides the foundation for future self and professional development [26] and vital in order to provide optimal care to patients [46].

Nursing/midwifery is the bedrock for health services and should be reinforced through regulation, management, education and research [16]. Research must be viewed as a process where educators continue to advance teaching strategies that focus on the necessary relationship between research and practice [45]. Thereby research needs to be communicated in a manner that is clear to practitioners [16]. Undergraduate students are not enthusiastic about research owing to minimal contact with research utilisation in clinical practice [16]. To enthuse students about research, they need to see the value of research and require research engagement throughout their curriculum [33]. Generally research modules only provide information to students that is the 'tip of the ice berg' and once completed the student must continue to develop their ability and knowledge of using the research process. Developing a blended approach to learning should make module content more meaningful, connect theory to practice and make the module more available to the diversity of learning styles [37]. However, in order to develop effective approaches for integrating evidence-based practice into the curriculum, it is essential that there is an understanding of the different sources of evidence that are used by students, how retrieving evidence can be problematic, the knowledge and attitude of students an, their current use of evidence-based practice $[2,13]$ and question what is stopping students from undertaking project work where they can confront a clinically pertinent question, find evidence to support it and implement the findings. However, students traditionally expect research to be a difficult subject to understand and the task facing educators is to amalgamate the correct elements to engage the student [73]. Aspects such as computer technology, retrieving information, utilising research and critical thinking skills have been acknowledged as fundamental for evidence-based practice [13].

Evidence-based practice compels the nursing/midwifery profession to critically appraise their practice and challenges personal bias, while honouring individual patient care requests. It also demands positive knowledge, skills and attitude to understand and apply research in clinical practice [72]. Using evidence-based information improves and updates clinical practice and enhances the quality of care and patient outcomes. However, its implementation remains a substantial and significant challenge [82]. Ax and Kincade (2001) conducted a study which found that students who proposed changes in the workplace, that were research based, felt undermined and the power exercised by more senior staff obstructed any proposed changes. Traditionally, research modules have been taught in a way which moulds students into evidence generators as opposed to the promotion of students as consumers of evidence [3]. If nursing/midwifery students are to foster a sense of discovery and exploration regarding the research process, then the responsibility for encouraging this discovery should be shared with the third level institutions, their lecturers and staff in the clinical areas.

Students need to be actively involved in research education and while students acknowledge that; while they would use newly attained knowledge in the workplace, they were disinclined to undertake research in the future [3]. To address this issue, lecturers must use education approaches that necessitate active engagement from the student, tackling and dismissing students' misunderstandings and build on students' existing knowledge [9]. Practitioners working in the health service have acknowledged the vast amount of research undertaken in order to enhance the delivery of evidenced-based care and different perspectives require different approaches to research [64].

\section{Assignment process}

At the start of the module students were informed of the learning objectives for the module, the assignment method, assignment process and allocation of topic areas. Students were to keep a journal of their learning experiences in line with the topics delivered each week. To start the process each student were to undertake a formative assessment on each topic area identifying their present level of knowledge and perceived deficits. This initial formative assessment was to allow students reflect on how their understanding and 
knowledge developed and changed over the course of the module. Students were to write their entries after each lecture and tutorial in a style and format of their choosing and students had the chance to ask questions and seek clarification at the end of each lecture and tutorial. Although students were provided with assessment guidelines they were free to decide on how best they would go about writing their summative assessment (learning log), with students making their own decision with regards to matters such as content, format, style and approach. Students were advised that the learning log must show evidence of critical analysis, self-awareness and learning [70]. Within the module outline and objectives students were made aware of the focus of the module; to enable students develop research knowledge and utilisation skills appropriate to a beginner level research consumer. The aspect involved in the module are highlighted in Table 1.

Table 1. Module learning and content.

\begin{tabular}{|c|c|}
\hline \multicolumn{2}{|c|}{$\begin{array}{l}\text { 1. Examine the research process. } \\
\text { 2. Examine research methodologies/methods used in nursing/ } \\
\text { midwifery. } \\
\text { 3. Evaluate research findings and apply to professional practice. }\end{array}$} \\
\hline A. Research process. & G. Ethical issues \\
\hline B. Research paradigms. & H. Sampling \\
\hline C. Research approaches. & I. Data collection \\
\hline D. Research question/aim/objectives & J. Data analysis \\
\hline E. Literature/database searches. & K. Rigour \\
\hline F. Critiquing literature. & L. Research utilisation \\
\hline
\end{tabular}

\section{Student comments (first author)}

As an undergraduate student of the BSc four year nursing degree programme, I completed a research module in my second year of my programme, using a learning log as a form of assessment. The assignment involved developing a learning log to reflect my journey through the steps of the research process. The modules aim was to progress understanding, attitude and skills to critically review research literature and apply to practice, promoting an appreciation of the impact research makes to practice. I had not used a learning log previously; therefore, it afforded me the opportunity to learn about the research process in a new and innovative way.

On starting this module I was concerned regarding the topic area as it was new to me as a subject, even though the concept of been evidence-based and research informed knowledge were embedded within our modules and practice placements to-date. My concern related to the fact that there were many new terms and philosophies to discover which I did not feel related specifically to patient care. An additional source of concern was that we could choose a methodology to fame our learning from a pre identified list developed by the module leader. All these methodologies were all new to me; I expressed my difficult in identifying a choice. This lead to a discussion within the group and an agreement that the module leader would either allocate or use a lottery system to allocate each student a methodology. As a group we decided that a lottery system seemed fairest as we were all in a similar situation. The allocated methodology was then utilised and applied to the module learning through the research process to examine its use in nursing/midwifery and its application and utilisation in practice. The first task was to conduct the formative assessment of an initial 500 word document outlining my thoughts and ideas regarding the methodology within the research process. Here the steps of the research process could be used as predetermined headings and other headings were encouraged if appropriate.

As we moved through the module I became aware that in identifying evidence a review of the literature was a pivotal starting point. The purpose of carrying out a literature review is to accumulate information about a specific area from diverse but appropriate sources [80]. The ability to conduct an effective literature search can provide an overview of contemporary thinking within a particular subject area and highlighting new areas of research $[29, \mathbf{8 5}$. I quickly discovered that while I had often searched for literature and used databases I was only operating at a novice level with limited searches been conducted of only one or two database (CINAHL, Medline). It became evident that the steps to a successful literature review include writing a research question, using key words and terms, using Boolean and Truncation searches and selecting appropriate databases. Within setting a research question I found [20] article on setting a research question, aim and objective/s supported me in this process. Exposure to other databases such as; Scopus, Web of Science, Academic Search Complete, PsychInfo and Embase broadened my information retrieval to evaluate the evidence and apply to my practice. A systematic, comprehensive and structured literature review will ultimately produce quality evidence. While this is a fundamental step I found this part of the learning log to be the most laborious, in devising my search strategy and conducting the searches with many results to be scanned.

My focus was on case study research and I observed that nurse/midwife researchers are using case studies to discover phenomena in healthcare practice. A key feature of case study research is its capacity to permit researchers to focus on intricate aspects while taking into account the circumstances of the situation [14]. There are many ethical challenges with case study research mainly due to the developing and changeable nature that can be involved. The main concerns involve the issues of; informed consent, researcher-participant relationship, risk-benefit ratio, confidentiality and dual role of the nurse-researcher. Samples within case study research stem for non-probability methods generally purposive with data collected through methods such as interviews, observations and documents. When analysing data the researcher searches for patterns in the data and when identified tries to understand them in terms of a social theory or the environment in which they occurred [55]. Following which the researcher 
Kerin et al. Journal of Nursing 2018,

moves from the description to an overall interpretation of its meaning with the goal of uncovering patterns, determining meanings, constructing conclusions and often building theory. To uphold rigour aspects employed include; prolonged engagement, persistent observation, triangulation, peer debriefing, member checking, audit trail, reflexivity, and thick descriptions [34].

My experience of the research learning log was mixed. New vocabulary and research terms had to be grappled with, while simultaneously delving into the world of research and all its connotations. I found that the submission of my initial thoughts was a very good anchorage point, as it allowed me to look at what existing knowledge I possessed regarding the research process, and allowed me to build on that knowledge. Guidelines given by the module leader were helpful initially as they laid out the structure of the learning log and inclusion criteria. As the completion of the learning log was mainly a self-directed task, it fostered and encouraged the skills of; time management, planning, goal setting and engaging in a supportive learning environment. Time was given by the module leader to answer questions and provide clarification on any topics. The fact that this was my first introduction to a learning log meant that I had to access many different sources of knowledge including books, journals and databases in order to acquire the appropriate knowledge and information needed to complete the leaning log. Weekly tutorials reinforced my learning by clarifying any issues that arose. Each section of the learning log was broken down into component parts enabling me to keep on track and remain focused on each sub-heading. The skill was then to unify all the headings into one fluid and comprehensive document and again, the assistance of the module leader at this point was crucial, ensuring that all relevant and vital components of the learning log were included.

Overall I found the use of a learning log enabled me to take more responsibility for my own learning and plan out the task at hand in a more productive manner. The use of the formative assessment allowed me to identify what I thought I knew and enabled me to open a dialogue in class or tutorials. This was important as it enabled me to seek clarification but also establish and reinforce the fact that I was on the right track and ensured I was going in the right direction. What was of note to me in conducting the formative and summative assessment was that when I completed my learning log I could see how my knowledge and skills had developed and progressed over time. The use of the learning log supported me to give time to each step in the research process, develop my understanding of each step and work in a friendly manner to complete tasks, and have a sense of completion and reward for the work done each week. This differed to most assignments where I generally engage in a mad rush near the end to pull things together to submit my assignment after spending many weeks wondering around looking and reading information but not having any of the real work in producing the end produce done.

\section{Module leader comments}

Students had no prior experience of a learning log and many students were originally very confused as to what it was or how to set about completing a learning log. Students found the idea of having to write in their learning log each week and to keep up-to-date throughout the 10 week module very frightening and demanding. Initial uneasiness was expressed in a number of ways mainly through ambiguity about what was required and confusion as to what was expected given that there was individuality in learning and a choice regarding its presentation (content, format, style and approach). This individuality created worry for students as there was no formal agreed template to operate from. However, as students engaged in the process and took ownership of their work they also began to take ownership of their own learning. This created awareness of their learning needs and how they best learn, thereby building their self-confidence not only in terms of their knowledge but also in relation to their ability to complete the assignment. This self-confidence enabled and encouraged students to engage in reading more often and engaging with course and published materials. Through reflecting on the experience the module leader were able to identify many challenges which related to the perceived difficulty of the task, constraints such as the word limit and uncertainty regarding the assessment. However, tutorials where students had the opportunity to ask questions and receive feedback from the module leader supported students within the process and created an environment that Christiansen and Bell (2010) see as cooperative learning [15]. The submission of the summative assessment at the end of the academic semester ( 13 weeks) allowed students to consolidate their learning and build upon the final lecturers and tutorials within the 10 week semester. Thus supporting students to plan and set realistic targets to assist them complete their work and learning.

\section{Discussion}

This paper explored the use of a learning log as an assessment method to facilitate and support students to understand research through the steps of the research process. As reflection is a vital ingredient in the research process learning logs have a positive contribution to make in the growth of students' knowledge, skills and attitudes, and act as an effective instrument for the appraisal of learning outcomes [68]. Developing students reflective and critical thinking skills are essential to enable them develop the link between theory and practice [32]. Furthermore students who actively engage with their subject tend to; apprehend more, learn more, recall more, enjoy it more and be more able to understand the significance of what they have learned [61]. Given that nurses/midwives need to use research in clinical practice to improve quality of care and treatment [36], simply reading papers is not sufficient as 
they require the capability to critically appraise the evidence prior to deciding if it should be incorporated into daily practice [28]. As a module of learning research provides students with confidence and knowledge to empower their clinical practice [12] and it is necessary to develop the self-regulated learning skills of undergraduate students [71]. However, research still remains a difficult subject to teach as many students struggle and find it difficult to understand research terminology, have an inability to grasp the concept of research and recognise its importance and link to practice $[24,43]$.

The importance of educators having a positive attitude, knowledge of research, a good theoretical base and enthusiasm to make learning exciting in teaching research cannot be underestimated [58]. Thus the use of creative teaching approaches and research competence assists in maintaining credibility and supports students $[\mathbf{2 7 , 6 9 ]}$. However, difficulties exist in overcoming cultural and abstract barriers to research in order to develop students' self-confidence in their capacity to understand and utilise research in their practice $[37,51]$. These barriers and the struggle to engage and communicate to students the importance and integral role that research plays in professional practice can be frustrating [75]. As a first step we must foster a passion for research and a wish to recognise how research links to the real world of practice [63]. Not just by teaching a research module but by incorporating the philosophies of evidence-based practice throughout the syllabus [13] and nurturing a spirit of inquiry in students as they advance through their education $[25,44]$. Approaches to teaching research can attribute to students' attitudes therefore educators play a vital role in students' development of evidence-based practice, knowledge, skill and co-ordination [81].

Given that pre-registration professional programmes should produce research conscious practitioners [4]. The location of research in a syllabus needs careful consideration as new students may not identify the significance of research to practice, but for students to be able to adopt evidence-based practice and practice evidence-based methods research cannot be deferred too long [4]. As critical thinking is the foundation upon which everything else is constructed [23], students need to engage in purposeful research activities to be better able to see the value of research for their practice [83]. Within this module there was a need to balance the fact that students found the learning process of research worrying [47] and that the use of a learning log was a daunting experience that can make students feel overwhelmed by the challenge of completing a continuous reflective log and feeling ill-equipped to do this effectively [53]. However, providing variety in teaching approaches assisted in involving students in active learning [38], teaching methods and curriculum assessment were given careful consideration and support in order to promote student commitment and enhance learning outcomes [30]. Providing support to students is essential as educators have a crucial role in arbitrating between research and practice making sure students can access, understand and support research evidence in practice [16]. What is important is the recognition that access and understanding is not adequate to ensure use in practice [47]. Given the vision of modern day practice is the developments of a scientific knowledge base enabling nurse/midwifes to implement evidence-based care [29], nurse/midwifes need to learn and understand the language of research [67].

Learning is an active process by which persons obtain new knowledge or skill and adjust thoughts, feelings, attitudes and actions [5]. As learning is a lifelong process and often self-directed, it is important students are ready for this process [8] and appreciate that thinking about thinking is really about themselves as learners, what they think about learning and how they can best learn [50]. To become self-governing, self-directed learner and reflective thinkers we need to understand what preparation for learning is required, observe it as it occurs, and then assess both what has been learned and how it was learned [84]. One of the main aspects to advance student learning is to provide a structure for students to reflect thoroughly during their programme on their learning process and to develop their capacities, skills and habits that are gained from critical reflection [86].

While research is the lifeblood of any profession and research findings are important in our endeavour to be evidence-based and provide high quality care [57]. The sheer amount of new information and new language can be overwhelming [65]. Nonetheless we need to encourage students capability and confidence in questioning current clinical practice [13] rather than students conforming to current clinical practice environments [44]. This conforming will occur where students lack knowledge, confidence or skill in relation to research components of evidence-based practice [77] or have a negative attitude to applying research in clinical practice [72]. To overcome this we require nurse/ midwifes to be skilled in a range of activities such as; detecting knowledge gaps, searching appropriate literature efficiently and appraising research evidence [81]. Engaging student in evidence-based practice and research enables them to develop an acceptance of the importance of evidence-based practice and care, promote research knowledge and skills, motivate and cultivate an interest in and an acceptance of evidencebased practice and research which would become rooted in their practice and continue past the point of registration [73]. This is essential as evidence-based practice is linked to clinical governance, safe and effective decision-making, and greater transparency and accountability $[49,52]$. As students become nurses/midwives they will be expected to exhibit proficiency and application of relevant research knowledge [19]. In doing so they assume the responsibility and accountability to provide safe, person-centred, evidence-based care [16], promoting their clinical decision-making [42].

\section{Conclusion}

Using a learning log as a form of assessment had many benefits 
Kerin et al. Journal of Nursing 2018,

http://www.hoajonline.com/journals/pdf/2056-9157-5-5.pdf

doi: $10.7243 / 2056-9157-5-5$

such as; acquiring skills in carrying out a literature search and review, understanding the different types of research and developing students' skills and understanding of research and how it can improve care within the health service, resulting in evidenced-based practice. Nurses/midwives are required to use evidence to inform the development and improvement of policies and practices in order to deliver quality care. Thus nurses/midwives need to develop research competence as they engage with evidence throughout their career and develop new knowledge to guide practice. In addition, nurses/ midwives need to learn to translate best evidence within their practice to impact the care provided, quality and costeffectiveness of that care $[35,78]$. Thereby fulfilling the goal of nursing/midwifery by providing evidence-based care that promotes quality outcomes for patients, family, and healthcare providers and system [18]. However, we need to ensure sufficient implementation of evidence in routine practice as there will always be a research-practice gap between publication and adoption of practices which could be between ten to thirty years [76].

\section{Competing interests}

The authors declare that they have no competing interests.

Authors' contributions

\begin{tabular}{|l|c|c|}
\hline Authors' contributions & OD & MK \\
\hline Research concept and design & $\checkmark$ & $\checkmark$ \\
\hline Collection and/or assembly of data & $\checkmark$ & $\checkmark$ \\
\hline Data analysis and interpretation & $\checkmark$ & $\checkmark$ \\
\hline Writing the article & $\checkmark$ & $\checkmark$ \\
\hline Critical revision of the article & $\checkmark$ & $\checkmark$ \\
\hline Final approval of article & $\checkmark$ & -- \\
\hline Statistical analysis & -- & -- \\
\hline
\end{tabular}

\section{Acknowledgements}

I would like to thank my fellow classmates, the University of Limerick and my placement sites during my four year degree programme for their support, encouragement and opportunity to develop my knowledge, skill and professional attitude (MK).

Publication history

Editor: Pamela gail Hawranik, Athabasca University, Canada. Received: 21-May-2018 Final Revised: 17-Jul-2018

Accepted: 19-Jul-2018 Published: 17-Aug-2018

\section{References}

1. An Bord Altranais agus Cnáimhseachais na h'Éireann. Nurse Registration Programmes Standards and Recommitments. fourth ed. An Bord Altranais agus Cnáimhseachais na h'Éireann, Dublin. 2016.| Pdf

2. August-Brady MM. Teaching undergraduate research from a process perspective. J Nurs Educ. 2005; 44:519-21. | PubMed

3. Ax S and Kincade E. Nursing students' perceptions of research: usefulness, implementation and training. J Adv Nurs. 2001; 35:161-70. | Article | PubMed

4. Badger FJ, Daly W and Clifford C. Educating tomorrow's clinical researchers: a review of research preparation in undergraduate education. Nurse Educ Today. 2012; 32:737-43. | Article | PubMed

5. Bastable S.B. Nurse as educator: Principles of teaching and learning for nursing practice. Fifth ed. Jones and Bartlett Learning, Boston. 2017.

6. Baumgartner P, Bergner I and Pullich L. Weblogs in education - A means for organisational change", multimedia applications in education conference (MApEC) proceedings. 2004 | Pdf

7. Benner P. From novice to expert, excellence and power in clinical nursing practice. Addison-Wesley Publishing Company, Menlo Park. 1984.

8. Benner P, Sutphen $M$, Leonard V and Day V. Educating nurse: A call for radical transformation. Jossey Bass, San Francisco. 2010.

9. Biggs J. Teaching for quality learning at university. Fourth ed. The Society for Research into Higher Education and Open University Press, Berkshire. 2011.

10. Bixler G.K. What is research. Nursing Research. 1952; 1:7-8.

11. Bridges E.J. Research at the bedside: It makes a difference. American Journal of Critical Care. 2015; 24:283-289. | Article

12. Brooke J, Hvalic-Touzery S and Skela-Savic B. Student nurse perceptions on evidence-based practice and research: an exploratory research study involving students from the University of Greenwich, England and the Faculty of Health Care Jesenice, Slovenia. Nurse Educ Today. 2015; 35:e6-e11. | Article | PubMed

13. Brown C.E, Kim S.C, Stichler J.F and Fields W. Predictors of knowledge, attitudes, use and future use of evidence-based practice among baccalaureate nursing/midwifery students at two universities. Nurse Education Today. 2013; 30:521-527.

14. Casey $D$ and Houghton $C$. Clarifying case study research: examples from practice. Nurse Res. 2010; 17:41-51. | Article | PubMed

15. Christiansen $A$ and Bell A. Peer learning partnerships: exploring the experience of pre-registration nursing students. J Clin Nurs. 2010; 19:803-10. | Article | PubMed

16. Christie J, Hamill C and Power J. How can we maximize nursing students' learning about research evidence and utilization in undergraduate, preregistration programmes? A discussion paper. J Adv Nurs. 2012; 68:2789-801. | Article | PubMed

17. Cochrane A.L. Effectiveness and efficiency: random reflections on health services (Vol. 900574178). Nuffield Provincial Hospitals Trust, London. 1972.

18. Craig, V and Smyth R.L. Evidence-based practice manual for nurses. Third ed. Churchill Livingstone, Edinburgh. 2012.

19. Daly J, Elliott $D$, Chang $E$ and Usher E. Research in nursing: concepts and processes. In: Daly, J., Speedy, S., Jackson, D., Contexts of Nursing. Fifth ed. Elsevier, Sydney. 2017; 129-142.

20. Doody $O$ and Bailey ME. Setting a research question, aim and objective. Nurse Res. 2016; 23:19-23. | Article | PubMed

21. Doody $O$ and Condon $M$. Increasing student involvement and learning through using debate as an assessment. Nurse Educ Pract. 2012; 12:2327. | Article | PubMed

22. Du H.S and Wagner C. Learning with Weblogs: An empirical investigation proceedings of the 38th Hawaii International conference on system sciences. 2005. I Website

23. Duncan $A$. The social studies are essential to a well-rounded education. Social Education. 2011; 75:124-125.

24. Ellis $P$. Understanding research for nursing students. Third ed. Learning Matters, Exeter. 2016.

25. Emerson RJ and Records K. Today's challenge, tomorrow's excellence: the practice of evidence-based education. J Nurs Educ. 2008; 47:359-70. I PubMed

26. Freeman M. Reflective logs: an aid to clinical teaching and learning. Int J Lang Commun Disord. 2001; 36 Suppl:411-6. | PubMed

27. Gillespie $M$ and McFetridge B. Nurse/midwife education - the role of the nurse teacher. Journal of Clinical Nursing. 2006; 15:639-644.

28. Greenhalgh T. How to read a paper: The basics of evidence-based medicine. Wiley-Blackwell BMJ Books, Chichester. 2014.

29. Gray J.R, Grove S.K and Sutherland S. Burns and Grove's: The practice of nursing research: Appraisal, synthesis and generation of evidence. Eight 
ed. Elsevier Saunders, St Louis. 2017.

30. Halcomb E.J and Peters K. Nursing student's feedback on undergraduate research education: Implications for teaching and learning. Contemporary Nurse. 2009; 33:59-68.

31. Hall H.R and Roussel L.A. Evidence-based practice: An integrative approach to research, administration, and practice. Second ed. Jones and Bartlett Learning, Burlington. 2017.

32. Hatlevik IK. The theory-practice relationship: reflective skills and theoretical knowledge as key factors in bridging the gap between theory and practice in initial nursing education. J Adv Nurs. 2012; 68:868-77. | Article | PubMed

33. Hawranik $P$ and Thorpe KM. Helping faculty enhance scholarship. $J$ Contin Educ Nurs. 2008; 39:155-63; quiz 164-5, 191. I PubMed

34. Houghton C, Casey D, Shaw D and Murphy K. Approaches to rigour in qualitative case study research. Nurse Researcher. 2013; 20:12-17.

35. Institute of Medicine. The future of nursing: Leading change, advancing health. The National Academies Press, Washington. 2011.

36. Jelsness-Jorgensen LP. Does a 3-week critical research appraisal course affect how students perceive their appraisal skills and the relevance of research for clinical practice? A repeated cross-sectional survey. Nurse Educ Today. 2015; 35:e1-5. | Article | PubMed

37. Johnson N, List-Ivankovic J, Eboh W.O, Ireland J, Adams D, Mowatt E and Martindale S. Research and evidence based practice: Using a blended approach to teaching and learning in undergraduate nurse/midwife education. Nurse Education in Practice. 2010; 10:43-47.

38. Kember D and McNaught C. Enhancing university teaching: Lessons from research into award-winning teachers. Routledge Taylor and Frances Group, London. 2007.

39. Kimble G.A. Hilgard and Marquis' conditioning and learning. AppletonCentury-Crofts, New York. 1961.

40. Kolb D.A. Experiential learning: Experience as the source of learning and development. Second ed. Pearson Education, New Jersey. 2015.

41. Kyrkjebo J.M and Hanestons B.R. Personal improvement project in nursing/midwifery education. Learning methods and tools for continuous quality improvement in nursing/midwifery practice. Journal of Advanced Nursing. 2003; 41:88-98.

42. Leach M.J. Clinical decision making in complementary and alternative medicine. Churchill Livingstone, Sydney. 2010.

43. Leach MJ, Hofmeyer A and Bobridge A. The impact of research education on student nurse attitude, skill and uptake of evidence-based practice: a descriptive longitudinal survey. J Clin Nurs. 2016; 25:194-203. | Article | PubMed

44. Levett-Jones T and Lathlean J. 'Don't rock the boat': Nursing students' experiences of conformity and compliance. Nurse Educ Today. 2009; 29:342-9. | Article | PubMed

45. Mansour TB and Porter EJ. Educators' experience of teaching nursing research to undergraduates. West J Nurs Res. 2008; 30:888-904. | Article I PubMed

46. de Oliveira AK and Tuohy D. Communication and nursing: a studyabroad student's reflections. Br J Nurs. 2015; 24:1080-2, 1084. | Article I PubMed

47. Mattila LR and Eriksson E. Nursing students learning to utilize nursing research in clinical practice. Nurse Educ Today. 2007; 27:568-76. | Article PubMed

48. McCurry MK and Martins DC. Teaching undergraduate nursing research: a comparison of traditional and innovative approaches for success with millennial learners. J Nurs Educ. 2010; 49:276-9. | Article | PubMed

49. McSherry R and Pearce P. Clinical governance: a guide to implementation for healthcare professionals. Third ed. Wiley-Blackwell, West Sussex. 2011.

50. Meek J, Riner M, Pesut D, Runshe D and Allam E. A pilot study evaluation of student reflective thinking in a doctor of nursing practice program. Journal of Nursing Education and Practice. 2013; 3:82-91. | Article

51. Meeker MA, Jones JM and Flanagan NA. Teaching undergraduate nursing research from an evidence-based practice perspective. J Nurs Educ. 2008; 47:376-9. | PubMed

52. Melnyk B.M and Fineout-Overholt E. Evidence-based practice in nursing and healthcare: A guide to best practice. Third ed. Lippincott Williams and Wilkins, Philadelphia. 2014.

53. Miller L, Divall S and Maloney A. Using the learning log to encourage reflective practice. Educ Prim Care. 2012; 23:50-5. I PubMed

54. Moon J. Learning Journals and Logs UCD Teaching and Learning/ Resources. 2010. I Pdf

55. Neuman W.L. Social research methods: Pearson New International Edition: Qualitative and quantitative approaches. Seventh ed. Pearson Education Limited, Essex. 2014.

56. Newton JM, McKenna LG, Gilmour C and Fawcett J. Exploring a pedagogical approach to integrating research, practice and teaching. Int J Nurs Educ Scholarsh. 2010; 7:Article3. | Article | PubMed

57. Ning $M$, Murphy $P$ and Jinks A.M. Research engagement and attitudes to teaching research to healthcare students: A questionnaire study of healthcare educators. Journal of Further and Higher Education. 2010; 34:537-556

58. Niven E, Roy DE, Schaefer BA, Gasquoine SE and Ward FA. Making research real: embedding a longitudinal study in a taught research course for undergraduate nursing students. Nurse Educ Today. 2013; 33:64-8. | Article | PubMed

59. Karstadt L. Standards for pre-registration nursing education: your view counts. Br J Nurs. 2010; 19:515. | Article | PubMed

60. Parahoo K. Nursing research: principles, process and issues. Palgrave Macmillan, Hampshire. 2014.

61. Park C. Engaging students in the learning process: The learning journal. Journal of Geography in Higher Education. 2003; 27:183-199. | $\underline{P d f}$

62. Pearce PF, Christian BJ, Smith SL and Vance DE. Research methods for graduate students: a practical framework to guide teachers and learners. J Am Assoc Nurse Pract. 2014; 26:19-31. | Article | PubMed

63. Phillips RM and Bonsteel $\mathrm{SH}$. The faculty and information specialist partnership: stimulating student interest and experiential learning. Nurse Educ. 2010; 35:136-8. | Article | PubMed

64. Polgar $S$ and Thomas $S$. Introduction to research in the health sciences. Sixth ed. Churchill Livingstone, London. 2013.

65. Polit D.F and Beck C.T. Essentials of nursing research: Appraising evidence for nursing practice. Ninth ed. Lippincott Williams and Wilkins, Philadelphia. 2017.

66. Rai A. Benefits of in-class debates as an instructional strategy. Economic Affairs. 2011; 56:139-145.

67. Rebar C.R and Gersch C.J. Using research in evidenced-based practice. Fourth ed. Wolters Kluwer Lippincott Williams and Wilkins, London. 2015.

68. Ross C, Mahal K, Chinnapen Y, Kolar M and Woodman K. Evaluation of nursing/midwifery students' work experience through the use of reflective journals. Mental Health Practice. 2014; 17:21-27.

69. Rossetti J and Fox PG. Factors related to successful teaching by outstanding professors: an interpretive study. J Nurs Educ. 2009; 48:116. | PubMed

70. Royal College of General Practitioners. How to produce good learning log entries. Workplace based assessment standards group, Royal College of General Practitioners, London. 2010.

71. Sandars J and Cleary TJ. Self-regulation theory: applications to medical education: AMEE Guide No. 58. Med Teach. 2011; 33:875-86. | Article | PubMed

72. Scott $K$ and McSherry R. Evidence-based nursing: clarifying concepts for nurse/midwifes in practice. Journal of Clinical Nursing. 2008; 10: 13651376.

73. Mary S, Julie J and Jennifer G. Teaching evidence based practice and research through blended learning to undergraduate midwifery students from a practice based perspective. Nurse Educ Pract. 2014; 14:220-4. | Article | PubMed 
Kerin et al. Journal of Nursing 2018,

74. Snelgrove $S$ and James M. Graduate nurse and midwives' perceptions of research. Journal of Research in Nursing. 2011; 16:7-20.

75. Spiers J.A, Paul P, Jennings D and Weaver K. Strategies for engaging undergraduate nursing/midwifery students in reading and using qualitative research. The Qualitative Report. 2012; 17:1-22.

76. Squires JE, Hutchinson AM, Bostrom AM, O'Rourke HM, Cobban SJ and Estabrooks CA. To what extent do nurses use research in clinical practice? A systematic review. Implement Sci. 2011; 6:21. | Article | PubMed Abstract | PubMed FullText

77. Stichler JF, Fields W, Kim SC and Brown CE. Faculty knowledge, attitudes, and perceived barriers to teaching evidence-based nursing. I Prof Nurs. 2011; 27:92-100. | Article | PubMed

78. Swenson-Britt $E$ and Reineck $C$. Research education for clinical nurses: a pilot study to determine research self-efficacy in critical care nurses. $J$ Contin Educ Nurs. 2009; 40:454-61. | Article | PubMed

79. Thomson P, Smith A and Annesley S. Exploration of the effects of peer teaching of research on students in an undergraduate nursing/ midwifery programme. Journal of Research in Nursing. 2014; 19:415430. | Article

80. Timmins $F$ and McCabe $C$. How to conduct an effective literature search. Nursing Standard. 2005; 20:41-47.

81. Upton P, Scurlock-Evans L, Williamson K, Rouse J and Upton D. The evidence-based practice profiles of academic and clinical staff involved in pre-registration nursing students' education: a cross sectional survey of US and UK staff. Nurse Educ Today. 2015; 35:80-5. | Article | PubMed

82. Veeramah $\mathrm{V}$. The use of evidenced-based information by nurses and midwives to inform practice. J Clin Nurs. 2016; 25:340-50. | Article | PubMed

83. Vessey JA and DeMarco RF. The undergraduate research fellows program: a unique model to promote engagement in research. $J$ Prof Nurs. 2008; 24:358-63. | Article | PubMed

84. Weimer M. Teaching metacognition to improve student learning. 2010. I Website

85. Younger P. Using Google Scholar to conduct a literature search. Nursing Standard. 2010; 24:40-46.

86. Zubizarreta J. The learning portfolio: Reflective practice for improving student learning. Second ed. Jossey-Bass, San Francisco. 2009.

\section{Citation:}

Kerin $\mathrm{M}$ and Doody O. Using a learning log to support students understanding and engagement within a research module. J Nurs. 2018; 5:5. http://dx.doi.org/10.7243/2056-9157-5-5 